\title{
IMPROVEMENT OF KNOWLEDGE AND ATTITUDE OF COMMUNITY FIGURE IN PREVENTING MALARIA DISEASE THROUGH DISCUSSION WITH LEAFLET AND MODULE
}

\author{
1| Fauziah Nasution*, 2| Putra Apriadi Siregar*, 3| Emmy Yustina** \\ Email Korespondensi : putraapriadisiregar@uinsu.ac.id \\ *Universitas Islam Negeri Sumatera Utara, Indonesia \\ **Dinas Kesehatan Kabupaten Langkat, Indonesia
}

\begin{abstract}
Malaria is an ancient disease, which is that still survive to this day, which is transmitted by the bite of Anopheles mosquito containing plasmodium, and poses a health problem that causes anemia, lowered work productivity and even death. Cases of clinical malaria in Langkat in the last three years has increased, which in 2010 from 47.18 per 1000 population increased to 63.79 per 1000 population in 2012. This type of research used in this study is quasi-experimental with a pretest-posttest design. The population in this study are all Community Leaders in Kutambaru Subdistrict, Langkat district totaling 36 people. The sample is the entire population, numbering 36 people were divided into 2 groups: with leaflet and modules media. Analysis of the data using a statistical test Wilcoxon. The results of this study showed that the average improvement of knowledge and attitude was more effectively obtained through leaflet media compared to using modules media.Discussions using leaflet media are more effective compared to the $p$ value module $(0,000)<\alpha(0.05)$. Discussion by using leaflet media is more effective than the module in improving the attitudes of community leaders $p(0,000)<a$ (0.05). It is recommended that the health extension workers Puskesmas Maryke more active in providing health education to the community leaders on the prevention of malaria by using media modules and leaflets.For community leaders to be more active in finding and conveying information about malaria prevention to the community in their respective villages.
\end{abstract}

Abstrak

Malaria adalah penyakit purba, sebuah penyakit bertahan hingga hari ini, yang ditularkan oleh gigitan nyamuk Anopheles yang mengandung plasmodium, dan menimbulkan masalah kesehatan yang menyebabkan anemia, menurunkan produktivitas kerja dan bahkan kematian. Kasus malaria klinis di Langkat dalam tiga tahun terakhir telah meningkat, yang pada 2010 dari 47,18 per 1.000 populasi meningkat menjadi 63,79 per 1.000 populasi pada 2012. Jenis penelitian yang digunakan dalam penelitian ini adalah quasi-eksperimental dengan desain pretest-posttest. Populasi dalam penelitian ini adalah semua Tokoh Masyarakat di Kecamatan Kutambaru, Kabupaten Langkat yang berjumlah 36 orang. Sampel adalah seluruh populasi, berjumlah 36 orang dibagi menjadi 2 kelompok: dengan media leaflet dan modul. Analisis data menggunakan uji statistik Wilcoxon. Hasil penelitian ini menunjukkan bahwa peningkatan rata-rata pengetahuan dan sikap lebih efektif diperoleh melalui media leaflet dibandingkan dengan menggunakan media modul. Diskusi menggunakan media leaflet lebih efektif dibandingkan dengan modul nilai $\mathrm{p}(0,000)$ $<\alpha(0,05)$. Diskusi dengan menggunakan media leaflet lebih efektif daripada modul dalam meningkatkan sikap tokoh masyarakat $\mathrm{p}(0,000)<\alpha(0,05)$. Disarankan bahwa petugas penyuluh kesehatan Puskesmas Maryke lebih aktif dalam memberikan pendidikan kesehatan kepada para pemimpin masyarakat tentang pencegahan malaria dengan menggunakan modul media dan selebaran. Untuk para pemimpin masyarakat agar lebih aktif dalam menemukan dan menyampaikan informasi tentang pencegahan malaria kepada masyarakat di desa masing-masing.

\section{Kata Kunci: Leaflet; Modul; Tokoh Masyarakat; Malaria}

\section{PENDAHULUAN}

Angka kesakitan malaria secara Nasional selama tahun 2005-2013 cenderung menurun dengan angka kesakitan 4,1 per 1.000 penduduk berisiko pada tahun 2005 menjadi 1,38 per 1.000 penduduk berisiko pada tahun 2013. Namun secara Nasional belum mencapai target Rencana Strategi Kementerian Kesehatan. Target Rencana Strategi Kementerian Kesehatan untuk angka kesakitan malaria API tahun 2013 
adalah 1,25 per 1.000 penduduk berisiko. Dengan demikian cakupan API 2013 tidak mencapai target Renstra 2013 (1)

Kasus malaria klinis atau AMI (Annual Malaria Incidence) 4 tahun terakhir di Propinsi Sumatera Utara cenderung mengalami peningkatan. Pada tahun 2010 AMI sebesar 27,77 per 1000 penduduk meningkat menjadi 36,09 per 1000 penduduk pada tahun 2012. Untuk angka SPR (Slide Positive Rate) dari 36,09\% pada tahun 2010 meningkat menjadi 38,51\% pada tahun 2012. Sementara itu API (Annual Paracite Incident) per 1000 penduduk untuk Sumatera Utara mencapai angka 0,84 pada tahun 2012 dan meningkat menjadi 1,3 pada tahun 2013 (1)

Malaria merupakan salah satu penyakit menular yang upaya penurunan kasusnya terkait komitmen internasional dalam MDGs. Kabupaten yang merupakan daerah endemis penyakit malaria di Provinsi Sumatera Utara adalah Asahan, Labuhan Batu, Langkat, Karo, Tapanuli Selatan, Mandailing Natal, Nias, dan Nias Selatan. Adapun 10 Penyakit terbesar di Kabupaten Langkat adalah ISPA, diare, hypertensi, malaria klinis, batuk rejan, DBD, Diare berdarah, TB BTA+, Tifus Perut dan Malaria Falciparum. Empat jenis penyakit terbesar yakni ISPA, Diare, hypertensi dan malaria klinis trendnya relatif mengalami peningkatan dari tahun 2009 ke 2011 (2).

Pada tahun 2011, dari 23 kecamatan yang ada di Kabupaten Langkat, 11 kecamatan diantaranya merupakan daerah endemis malaria. Dari 11 kecamatan tersebut mencakup 13 wilayah kerja Puskesmas. Pada tahun 2005, kejadian malaria terbanyak terjadi di wilayah pesisir Langkat yang sering disebut Langkat Hilir. Namun mulai tahun 2009, dari data diperoleh bahwa insiden malaria ditemukan di daerah pegunungan dan dataran tinggi yang termasuk dalam wilayah Langkat Hulu. Salah satunya wilayah endemis malaria tersebut berada di Kecamatan Kutambaru yang berada di wilayah kerja Puskesmas Maryke. Angka Kejadian Malaria di Kabupaten Langkat khususnya Kecamatan Kutambaru setiap tahunnya meningkat, dikarenakan situasi dan kondisi lingkungan yang berada di dataran tinggi dan pegunungan serta curah hujan yang cukup tinggi menjadikan wilayah kecamatan kutambaru menjadi salah satu daerah endemis malaria. Kasus malaria klinis di Kabupaten Langkat pada tiga tahun terakhir mengalami peningkatan, dimana kasus malaria klinis pada tahun 2010 dari 47,18 per 1000 penduduk meningkat menjadi 63,79 per 1000 penduduk ditahun 2012 (2).

Pencegahan malaria, tidak hanya menjadi tugas dan tanggung jawab petugas kesehatan, namun menjadi tugas dan tanggung jawab seluruh lapisan masyarakat. Tingkat pengetahuan menjadi salah satu faktor yang mempengaruhi masyarakat dalam keikutsertaannya dalam upaya pencegahan malaria. Ibrahim (3) mengungkapkan bahwa masih banyak masyarakat penderita malaria yang kurang 
memilliki pengetahuan tentang penyakit malaria. Pengetahuan seseorang akan dipengaruhi oleh persepsi mereka tentang penyakit tersebut (4).

Faktor lingkungan dalam rumah yang berpengaruh secara signifikan adalah kondisi dinding rumah, pencahayaan dalam ruangan, dan pakaian tergantung serta yang tidak berpengaruh secara signifikan adalah penggunaan kawat kasa dan keberadaan langit-langit/plafon (5). Terdapat hubungan antara keberadaan langitlangit, jenis dinding, keberadaan resting places, breeding places, aktivitas luar rumah, penggunaan pakaian panjang, penggunaan kelambu, dan kegiatan bersih lingkungan dengan kejadian penyakit malariadi Wilayah Kerjas Puskesmas Kokap II (6).

Upaya Promosi Kesehatan rutin dilakukan dalam rangka memberantas malaria. Tokoh masyarakat memiliki peran yang cukup dalam membantu penyampaian pesan kepada masyarakat. Salah satu peran tokoh masyarakat adalah sebagai motivator untuk mendorong masyarakat dengan cara membujuk masyarakat agar ikut serta melaksanakan kegiatan-kegiatan yang diprogramkan. Berbagai penelitian dengan menggunakan metode-metode dan media promosi kesehatan sudah dilakukan di beberapa tempat di Indonesia. Upaya pemberantasan penyakit malaria di Kabupaten Langkat pada umumnya dan wilayah puskesmas Maryke Kecamatan Kutambaru pada khususnya telah dilakukan sesuai program yang ada. Upaya pencegahan yang dilakukan berupa kegiatan pengendalian vektor, pembagian kelambu, pemeriksaan jentik, melakukan pengobatan pada penderita klinis maupun penderita dengan konfirmasi laboratorium, dan melibatkan sektor terkait serta peningkatan peran serta masyarakat. Adapun tujuan penelitian ini adalah untuk menganalisis efektivitas metode diskusi dengan menggunakan media leaflet dan modul terhadap peningkatan pengetahuan dan sikap tokoh masyarakat tentang pencegahan malaria di Kecamatan Kutambaru Kabupaten Langkat..

\section{METODOLOGI PENELITIAN}

Jenis penelitian yang digunakan dalam penelitian ini adalah eksperimen semu (quasi experiment). Lokasi penelitian adalah wilayah kerja Puskesmas Maryke Kecamatan Kutambaru Kabupaten Langkat. Alasan pemilihan lokasi ini karena wilayah tersebut merupakan daerah endemis malaria, dan belum pernah dilakukan penelitian yang sama di kecamatan tersebut.

Penelitian ini dilakukan pada bulan Februari 2017 - Agustus 2017. Populasi penelitian adalah keseluruhan subjek penelitian Populasi dalam penelitian ini adalah seluruh tokoh masyarakat yang ada di Kecamatan Kutambaru Kabupaten Langkat yang berjumlah 36 orang. Kemudian peneliti membagi seluruh sampel menjadi 2 kelompok sampel dengan jumlah yang sama yaitu 18 orang per kelompok. 
Instrument dalam penelitian ini menggunakan kuesioner berstruktur yang telah dipersiapkan. Analisis bivariat dilakukan untuk menguji efektivitas metode diskusi dengan media leaflet dan modul dalam meningkatkan pengetahuan dan sikap tokoh masyarakat tentang Pencegahan Malaria di Kecamatan Kutambaru tahun 2015 dengan menggunakan statistik uji Wilcoxon dengan tingkat kepercayaan 90\% kemudian hasilnya dinarasikan.

\section{HASIL DAN PEMBAHASAN}

\section{Diskusi tentang Pencegahan Malaria dengan Media Leaflet}

Berdasarkan hasil penelitian diketahui bahwa semua item pertanyaan pengetahuan mengalami peningkatan, dimana sebelum diskusi, sebagian besar pengetahuan responden pada kategori kurangdengan jumlah 13 orang (72,2\%). Setelah diberikan perlakuan, responden berpengetahuan baik berjumlah 10 orang (55,6\%). Setelah diskusi diketahui bahwa pada kelompok leaflet terjadi peningkatan pengetahuan antara $19,1 \%$ sampai $55,6 \%$, dapat dilihat pada tabel berikut :

Tabel 1. Frekuensi Tingkat Pengetahuan Responden pada Pretest dan Posttest pada Kelompok Diskusi dengan Media Leaflet dan Modul

\begin{tabular}{ccccc}
\hline \multirow{2}{*}{ Pengetahuan } & \multicolumn{2}{c}{ Pretest } & \multicolumn{2}{c}{ Posttest } \\
\cline { 2 - 5 } & $\mathbf{n}$ & $\mathbf{0}$ & $\mathbf{0}$ \\
\hline Leaflet & 2 & 11,1 & 10 & 55,6 \\
Baik & 3 & 16,7 & 6 & 33,3 \\
Cukup & 13 & 72,2 & 2 & 11,1 \\
Kurang & & & & \\
Modul & 0 & 0,0 & 5 & 27,8 \\
Baik & 4 & 22,2 & 11 & 61,1 \\
Cukup & 14 & 77,8 & 2 & 11,1 \\
Kurang & & & &
\end{tabular}

Hasil penelitian ini menunjukkan bahwa sebelum pemberian perlakuan, sebagian besar tokoh masyarakat berpengetahuan kurang dengan jumlah 13 orang $(72,2 \%)$ pada kelompok leaflet dan 14 orang $(77,8 \%)$ pada kelompok modul. Setelah diberikan perlakuan diketahui bahwa sebagian besar responden berpengetahuan baik dengan jumlah 10 orang $(55,6 \%)$ pada kelompok leaflet dan berpengetahuan cukup dengan jumlah 11 orang $(61,1 \%)$ pada kelompok modul.

Hasil penelitian ini menunjukkan bahwa nilai rata-rata pengetahuan tokoh masyarakat sebelum perlakuan diskusi dengan media leaflet adalah 8,8, dan sesudah perlakuan meningkat menjadi 13,1 pada post test. Hal ini menunjukkan bahwa terjadi peningkatan pengetahuan tentang pencegahan malariasesudah pemberian perlakuan dengan media leaflet. 
Tabel 2. Frekuensi Tingkat Sikap Responden pada Pretest dan Posttest pada Kelompok Diskusi dengan Media Leaflet dan Modul

\begin{tabular}{lcccc}
\hline \multirow{2}{*}{ Sikap } & \multicolumn{2}{c}{ Pretest } & \multicolumn{2}{c}{ Posttest } \\
\cline { 2 - 5 } & $\mathbf{n}$ & $\mathbf{\%}$ & $\mathbf{n}$ & $\mathbf{\%}$ \\
\hline Media Leaflet & 0 & 0,0 & 11 & 61,1 \\
Baik & 6 & 33,3 & 5 & 27,8 \\
Cukup & 12 & 66,7 & 2 & 11,1 \\
Kurang & & & & \\
Media Modul & 0 & 0,0 & 5 & 27,8 \\
Baik & 5 & 27,8 & 10 & 55,6 \\
Cukup & 13 & 72,2 & 3 & 16,7 \\
Kurang & & & & \\
\hline
\end{tabular}

Dari hasil penelitian, diperoleh nilai rata-rata pengetahuan tokoh masyarakat sebelum perlakuan diskusi dengan media leaflet adalah 8,8 , dan sesudah perlakuan meningkat menjadi 13,1 pada post test. Hal ini menunjukkan bahwa terjadi peningkatan pengetahuan tentang pencegahan malaria sesudah pemberian perlakuan dengan media leaflet.

Perbedaan pengetahuan tokoh masyarakatdilihat dari hasil statistik dengan menggunakan uji Wilcoxon, nilai $\mathrm{p}<\alpha(0,05)$ yang artinya terdapat perbedaan yang bermakna antara pengetahuan tokoh masyarakat tentang pencegahan malaria sebelum dan sesudah pemberian perlakuan dengan media leaflet.

Dari hasil tersebut dapat disimpulkan bahwa terjadi peningkatan pengetahuan dan sikap setelah diberikan perlakuan diskusi dengan menggunakan media leaflet. Hal ini dapat memberikan gambaran bahwa diskusi dengan media leaflet cukup efektif dalam meningkatkan pengetahuan dan sikap tokoh masyarakat Kecamatan Kutambaru tentang pencegahan malaria. Respon yang positif dari tokoh masyarakat dan isi leaflet yang singkat dan padat dapat menjadi penyebab terjadinya peningkatan pengetahuan dan sikap setelah perlakuan.

Tabel 3. Perbedaan Efektivitas Diskusi tentang pengetahuan tentang Pencegahan Malaria dengan Media Leaflet dan Modul

\begin{tabular}{lccl}
\hline Media Penyuluhan & Mean & $\begin{array}{c}\text { Std. } \\
\text { Deviation }\end{array}$ & P \\
\hline Leaflet & 6.34 & 1.49 & \\
Modul & 3.32 & 1.42 & $<0,001$ \\
\hline
\end{tabular}

Hasil penelitian ini menunjukkan bahwa nilai rata-rata pada selisih pengetahuan responden untuk media leaflet sebesar 4,21 dan standar deviasi sebesar 1,49 , sedangkan untuk modulsebesar 2,13 dan standar deviasi 1,38, hasil uji statistik 
nilai $p(0,000)<\alpha(0,05)$.Hal ini menunjukan bahwa ada perbedaan nilai rata-rata selisih peningkatan pengetahuan antara media leaflet dengan modul, artinya bahwa diskusi dengan menggunakan media leaflet lebih efektif dibandingkan dengan modul dalam meningkatkan pengetahuan tokoh masyarakat tentang pencegahan malaria di Kecamatan kutambaru Kabupaten Langkat.

Tabel 4. Perbedaan Efektivitas Diskusi tentang sikap tentang Pencegahan Malaria dengan Media Leaflet dan Modul

\begin{tabular}{lccc}
\hline Media Penyuluhan & Mean & $\begin{array}{c}\text { Std. } \\
\text { Deviation }\end{array}$ & P \\
\hline Leaflet & 6.34 & 1.49 & \\
Modul & 3.32 & 1.42 & $<0,001$ \\
\hline
\end{tabular}

Hasil penelitian ini menunjukkan bahwa nilai rerata pada selisih sikap responden untuk media leaflet sebesar 6,34 dan standar deviasi sebesar 1,49, sedangkan modul sebesar 3,32 dan Standar deviasi sebesar 1,42 dengan hasil uji statistik menunjukan bahwa nilai $p(0,000)<\alpha(0,05)$, artinya bahwa ada perbedaan nilai rata-rata peningkatan sikap antara media leaflet dengan modul, artinya diskusidengan menggunakan media leaflet lebih efektif dibandingkan dengan modul dalam meningkatkan sikap tokoh masyarakat tentang pencegahan malaria di Kecamatan Kutambaru Kabupaten Langkat.

\section{Perbedaan Pengetahuan tentang Pencegahan Malaria dengan Media Leaflet dan Modul}

Menurut Kemenkes RI (7) bahwa media merupakan instrument yang penting dalam meningkatkan pengetahuan. Upaya pemberian informasi ditujukan agar informasi yang akan diberikan dapat diterima dengan baik oleh kelompok masyarakat dan efektif untuk merubah pengetahuan dan sikap terhadap pencegahan malaria

Perbedaan pengetahuan tokoh masyarakat dilihat dari hasil statistik dengan menggunakan uji Wilcoxon, nilai $\mathrm{p}<\alpha(0,05)$ yang artinya terdapat perbedaan yang bermakna antara pengetahuan tokoh masyarakat tentang pencegahan malaria sebelum dan sesudah pemberian perlakuan dengan media leaflet.

Hal ini sejalan dengan penelitian yang dilakukan oleh Harahap (8), dengan hasil bahwa menunjukkan metode diskusi lebih efektif dalam meningkatkan pengetahuan dan sikap perawat dalam membuang limbah medis padat di Puskesmas Kota Medan tahun 2010. Hasil tersebut juga sejalan dengan penelitian Tarigan (9), dari hasil penelitian menunjukkan bahwa rata-rata selisih skor pengetahuan dan sikap 
tertinggi terjadi pada kelompok yang mendapat perlakuan penyuluhan dengan metode diskusi kelompok dibandingkan ceramah.

Penelitian Bangun (10) menunjukkan bahwa pengetahuan dan sikap kedua kelompok intervensi sebelum diberikan pembelajaran dengan media leaflet mayoritas setara yaitu berpengetahuan dan bersikap kurang baik. Penelitian Alfianur (11) memperlihatkan bahwa terdapat pengaruh signifikan dalam peningkatan sikap siswa sebelum dan sesudah pemberian pendidikan kesehatan dengan media leaflet

Dari uraian di atas dapat diketahui bahwa media leaflet lebih efektif dibanding media modul. Peningkatan pengetahuan dan sikap tokoh masyarakat yang mendapat perlakuan dengan menggunakan media leaflet lebih tinggi dibandingkan dengan tokoh masyarakat yang mendapat perlakuan dengan menggunakan media modul, disebabkan karena pada media leaflet isi pesan lebih singkat dan jelas, serta mudah dimengerti, sehingga tokoh masyarakat lebih dapat memahami isi pesan dibandingkan dengan modul yang lebih tebal, berisikan informasi yang lebih panjang dan membutuhkan waktu yang lebih lama untuk mempelajarinya sehingga dapat menyebabkan tokoh masyarakat malas untuk membaca modul tersebut.

Secara keseluruhan, responden terbanyak terdapat pada usia 21-30 tahun sebanyak 8 orang $(44,5 \%)$ pada kelompok leaflet dan terdapat pada usia 31-40 tahun sebanyak 9 orang (50\%) pada kelompok leaflet. Sedangkan pada karakteristik pendidikan, responden terbanyak terdapat pada tingkat pendidikan minimal D3 sebanyak 12 orang $(66,7 \%)$ pada kelompok leaflet dan sebanyak 10 orang $(55,6 \%)$ pada kelompok modul. Hal tersebut dapat menjadi acuan bahwa tingkat pendidikan berpengaruh dalam penggunaan media.

Hal ini sejalan dengan penelitian Nur (12) yang menyatakan bahwa terdapat hubungan yang positif antara usia, tingkatpendidikan, dan jenis kelamin terhadap perilaku konsumsi media cetak. Siregar (13) menunjukkan bahwa perilaku seseorang dipengaruhi oleh karakteristik seperti tingkat pendidikan, pengalaman dan pendapatan. Penelitian Nurazizaturrahmah (14) menunjukkan bahwa peningkatan pengetahuan pada responden yang mendapat penyuluhan dengan menggunakan media leaflet.

Nurmawati (15) menyebutkan bahwa modul menjadi bagian penting dalam peningkatan pengetahuan dan sikap terutama dalam kegiatan pelatihan. Modul dan leaflet bisa digunakan dalam penyuluhan kepada masyarakat dalam upaya membantu penyampaian materi kepada masyarakat.

Hal tersebut berarti bahwa Leaflet lebih singkat, sehingga pesan yang ada di dalam leaflet tersebut lebih mudah diserap oleh individu yang membacanya. Sedangkan modul lebih tebal dan panjang penjabaran pesan yang hendak 
disampaikan, sehingga membutuhkan waktu yang lebih lama bagi individu yang ingin mempelajarinya.

Hal ini sejalan dengan penelitian yang dilakukan oleh Dian (16) Dari hasil, didapatkan hubungan yang sangat bermakna antara penggunaan modul dengan pengetahuan ibu tentang manajemen laktasi pasca melahirkan $(\mathrm{p}=0,000)$ dan efektivitas penggunaan modul dalam meningkatkan pengetahuan ibu tentang manajemen laktasi pasca melahirkan sebesar 75\%. Hasil penelitian juga sejalan dengan penelitian Sari (17), dimana dalam penelitiannya diperoleh hasil bahwa terdapat ada peningkatan yang signifikan pada pengetahuan seksual siswa yang mendapat perlakuan dengan menggunakan media modul.

Hasil penelitian ini sejalan juga dengan penelitian yang dilakukan oleh Wahyuningsih (18) yang membuktikan bahwa peningkatan pengetahuan pada kelompok dengan pemberian media modul kurang dibanding dengan media leaflet. Leaflet lebih efektif untuk meningkatkan pengetahuan tentang pernikahan dini. Hasil Penelitian ini, dalam hal sikap sejalan dengan penelitian yang dilakukan oleh Mendri (19) yang membuktikan bahwa Sikap responden dan kesiapan menghadapi menarche pada kelompok perlakuan dan pembanding sebelum diberikan modul sebagian besar kategori cukup dan setelah di berikan modul sebagian besar kategori cukup. Pada kelompok perlakuan yang diberikan modul lebih rendah rata-rata nilai kesiapan menghadapi menarche dibandingkan yang diberikan leaflet.

Dengan adanya penelitian ini, diketahui bahwa penyampaian pesan tentang pencegahan malaria dapat dilakukan dengan mengadakan diskusi terhadap para tokoh masyarakat.Tokoh masyarakat merupakan kelompok yang memiliki peranan di desa dan berinteraksi langsung terhadap masyarakat. Hal ini dapat menjadi salah satu alasan untuk dapat memberdayakan para tokoh masyarakat dalam membantu program pencegahan penyakit khususnya malaria. Pemberdayaan tersebut dapat dilakukan dengan sosialisasi terhadap para pokoh masyarakat melalui diskusi dengan menggunakan media untuk meningkatkan pengetahuan dan sikap

Pengetahuan dan sikap tokoh masyarakat tentang pencegahan malaria ini sangat perlu untuk ditingkatkan agar mereka mampu menyampaikan informasi tersebut kepada masyarakat disekitarnya untuk membantu menurunkan kejadian malaria di Kecamatan Kutambaru. Setelah diadakan penelitian ini, diperoleh kesimpulan bahwa media leaflet lebih efektif dibandingkan dengan modul dalam meningkatkan pengetahuan dan sikap tokoh masyarakat, sehingga hal tersebut dapat digunakan selanjutnya untuk menjalankan program pencegahan malaria.

Dengan adanya penelitian ini diharapkan agar tokoh masyarakat yang telah mendapat informasi tentang pencegahan malaria mampu membagikan ilmu yang 
didapat kepada masyarakat. Selain itu tokoh masyarakat dapat lebih aktif lagi dalam penyampaian informasi terkait pencegahan malaria kepada masyarakat yang memiliki lingkungan yang endemis malaria.

\section{KESIMPULAN DAN SARAN}

\section{Kesimpulan}

Terjadi peningkatan pengetahuan dan sikap setelah diskusi baik dengan media leaflet maupun modul. Sebelum diskusi, sebagian besar tokoh masyarakat berpengetahuan kurang, bersikap kurang terhadap pencegahan malaria dan setelah diskusi, sebagian besar responden berpengetahuan cukup dan baik, bersikap cukup dan baik tentang malaria Diskusi dengan media leaflet lebih efektif meningkatkan pengetahuan dan sikap tokoh masyarakat tentang pencegahan malaria dibandingkan dengan modul.

\section{Saran}

Bagi pihak Kecamatan agar dapat membantu memfasilitasi para tokoh masyarakat sehingga para tokoh masyarakat mau dan mampu menyampaikan informasi yang mereka peroleh kepada masyarakat di desa masing-masing. Bagi tokoh masyarakat agar lebih aktif dalam mencari dan menyampaikan informasi tentang pencegahan malaria kepada masyarakat di desa masing-masing. Bagi dinas Kesehatan agar lebih memperhatikan tokoh masyarakat yang dapat diberdayakan dan diikutsertakan dalam program pencegahan penyakit khususnya malaria dengan memberikan pelatihan-pelatihan.

\section{DAFTAR PUSTAKA}

1. Kementerian Kesehatan RI. Riset Kesehatan Dasar 2014. Penelitian dan Pengembangan Kesehatan Kementerian Kesehatan RI. 2014.

2. Dinas Kesehatan Kabupaten Langkat. Profil Kesehatan Kabupaten Langkat tahun 2013. Dinas Kesehatan Kabupaten Langkat.

3. Ibrahim I. Tingkat Pengetahuan Masyarakat tentang Penyakit Malaria di Tanjung Kertang Kelurahan Rempang Cate. Jurnal Ilmiiah Zona Kesehatan. 2017;11(3):54-62.

4. Nasution F, Rusman AA, Apriadi P. The Parent Perception Of Early Sex Education In Children At Simatahari Village, The Sub District Of Kotapinang, The District Of Labuhanbatu Selatan. INTERNATIONAL JOURNAL ON LANGUAGE, RESEARCH AND EDUCATION STUDIES. 2019 Jan 6;3(1):85-93.

5. Irawati I, Ishak H, Arsin A. Karakteristik Lingkungan Penderita Malaria di Kabupaten Bulukumba. Afiasi : Jurnal Kesehatan Masyarakat. 2017;2(3):73-7.

6. Noviarti PI, Joko T, Dewanti NAY. Hubungan Faktor Lingkungan Fisik dan Perilaku Penghuni Rumah dengan Kejadian Penyakit Malaria di Wilayah Kerja 
Puskesmas Kokap II, Kabupaten Kulon Progo, Daerah Istimewa Yogyakarta. Jurnal Kesehatan Masyarakat (e-Journal). 2016 Mar 2;4(1):417-26.

7. Kementerian Kesehatan. Panduan media penyuluhan. In: Panduan Media penyuluhan. Jakarta: Kementerian Kesehatan RI; 2012. p. 19-21.

8. Harahap YS. Efektivitas Metode Diskusi Dan Ceramah Terhadap Pengetahuan Dan Sikap Perawat Dalam Membuang Limbah Medis Padat Di Puskesmas Kota Medan Tahun 2010 [Internet] [Tesis]. [Medan]: Universitas Sumatera Utara; 2011 [cited 2019 Dec 27]. Available from: http://repository.usu.ac.id/handle/123456789/27588

9. Tarigan APS. Efektivitas Metode Ceramah Dan Diskusi Kelompok Terhadap Pengetahuan Dan Sikap Tentang Kesehatan Reproduksi Pada Remaja Di Yayasan Pendidikan Harapan Mekar Medan [Internet] [Tesis]. [Medan]: Universitas Sumatera Utara; 2011 [cited 2019 Dec 27]. Available from: http://repository.usu.ac.id/handle/123456789/21925

10. Bangun EH. Efektivitas Metode Ceramah Terhadap Pengetahuan Dan Sikap Keluarga Dalam Penanganan Tuberkulosis Paru Di Wilayah Kerja Puskesmas Guguk Panjang Kota Bukittinggi [Internet] [Tesis]. [Medan]: Universitas Sumatera Utara; 2011 [cited 2019 Dec 27]. Available from: http://repository.usu.ac.id/handle/123456789/30158

11. Alfianur A. Efektifitas Metode Ceramah Dengan Media Leaflet Terhadap Perubahan Perilaku Siswa Kelas 5 Dalam Pencegahan Penyakit Demam Berdarah (Dbd). JURNAL SUMBER DAYA MANUSIA KESEHATAN [Internet]. 2015 [cited 2019 Dec 27];2(1). Available from: http://id.portalgaruda.org/?ref=browse \&mod=viewarticle\&article=286658

12. Nur A. Pengaruh Usia, Tingkat Pendidikan, Dan Jenis Kelamin Terhadap Perilaku Konsumsi Media [Internet] [Skripsi]. Universitas Diponegoro; 2014 [cited 2019 Dec 27]. Available from: https://ejournal3.undip.ac.id/index.php/interaksionline/article/view/6494

13. Siregar PA. Perilaku Ibu Nifas dalam Mengkonsumsi Kapsul Vitamin A di Kecamatan Kota Pinang Kabupaten Labuhanbatu Selatan. Jurnal Kesehatan. 2019 May 16;12(1):47-57.

14. Nur'Azizaturrahmah. Perbedaan Pengetahuan Antara Sebelum Dan Sesudah Intervensi Penyuluhan Menggunakan Media Leaflet Tentang Penyebab Dermatitis Dan Pencegahannya Pada Pekerja Proses Finishing Mebel Kayu Di Ciputat Timur Tahun 2013 [Internet] [Skripsi]. [Jakarta]: Universitas Islam Negeri Syarif Hidayatullah Jakarta; 2015 [cited 2019 Dec 27]. Available from: http://repository.uinjkt.ac.id/dspace/handle/123456789/26508

15. Nurmawati I, Erawantini F. Efektivitas Metode Promosi Kesehatan dalam Meningkatkan Pengetahuan Kesehatan Reproduksi Remaja. Pros Semin Nas Pengabdi Kpd Masy dan Penelit Pranata Lab Pendidik Politek Negeri Jember. 2017;1:79-84.

16. Dian R, Lutfatul L, Rahmawati E. Efektivitas Modul untuk Manajemen Laktasi Pasca Melahirkan | Ramawati | Jurnal Keperawatan Soedirman. 2013 [cited 2019 Dec 27];8(1). Available

from: http://jks.fikes.unsoed.ac.id/index.php/jks/article/view/465

17. Sari NN. Efektivitas Pemanfaatan Modul Bimbingan Seksual DalamMeningkatkanPengetahuan Seksual Sehat Pada Siswa SMP. Jurusan 
Bimbingan dan Konseling [Internet] [Skripsi]. [Malang]: Universitas Negeri Malang; 2014 [cited 2019 Dec 27]. Available from: http://karyailmiah.um.ac.id/index.php/BK-Psikologi/article/view/35863

18. Wahyuningsih W. Pengaruh Pemberian Modul Terhadap Peningkatan Pengetahuan Tentang Pernikahan Dini Dan Rencana Umur Menikah Pertama Pada Siswi SMPN 1 Wonosari Gunung Kidul Tahun 201. Jurnal Teknologi Kesehatan. 2015;11(1).

19. Mendri NK. Pengaruh Penggunaan Modul Tentang MenarcheTerhadap Pengetahuan Dan Kesiapan Menghadapi MenarchePada Siswi Kelas V Sekolah Dasar Di Kecamatan Gamping Kabupaten Sleman Yogyakarta. Jurnal Kesehatan SAMODRA ILMU. 2014;5(2). 